\title{
SOBRE O MATERIAL-TIPO DE ANDANUS BIMACULATUS LINNAVUORI E DESCRIÇÃO DE UM NOVO GÊNERO E NOVA ESPÉCIE (HOMOPTERA, CICADELLIDAE, DELTOCEPHALINAE) ${ }^{1}$
}

\author{
Keti Maria Rocha Zanol ${ }^{2}$
}

\begin{abstract}
ON THE TYPE MATERIAL OF ANDANUS BIMACULATUS LINNAVUORI AND DESCRIPTION OF A NEW GENUS AND SPECIES (HOMOPTERA, CICADELLIDAE, DELTOCEPHALINAE). Linnavuori, 1959 described the genus and species Andanus bimaculatus based on four specimens collected in Peru, Madre de Díos. In examining the type-material, we found that it was formed by two species belonging to a different genus. The female specimen (alotype) and one of the two males paratypes, that Linnavuori used to dissect the genitalia, is here described as Perundanus raunoi, gen.n., sp.n. For a better characterization of the genus Andanus Linnavuori and A. bimaculatus Linnavuori, both are redescribed.

KEY WORDS. Homoptera, Cicadellidae, Deltocephalinae, Andanus bimaculatus, Perundanus raunoi
\end{abstract}

Linnavuori, em 1959, descreveu o gênero e espécie Andanus bimaculatus com base em quatro exemplares (holótipo macho, alótipo fêmea, e dois parátipos machos), provenientes de Peru, Madre de Díos. Em mãos o material-tipo, verificou-se que se constituía de duas espécies bem distintas, pertencentes a gêneros diferentes, apesar da grande semelhança morfológica externa. Os exemplares fêmea (alótipo) e um dos parátipos macho que Linnavuori utilizou para preparação da genitália, passam a ser Perundanus raunoi, gen.n., sp.n., que é descrita a seguir. Para melhor caracterização, redescreve-se Andanus Linnavuori e $A$. bimaculatus Linnavuori.

$\mathrm{O}$ material examinado pertence às seguintes Instituições: Hungarian Natural History Museum (HNHM) e American Museum of Natural History (AMNH).

\section{Andanus Linnavuori}

Andanus Linnavuori, 1959:237; espécie-tipo: Andanus bimaculatus Linnavuori, 1959 (desig. orig.).

Cabeça de comprimento uniforme. Região discal lisa. Sutura coronal ultrapassando a metade do comprimento da coroa. Ocelos não visíveis de cima.

1) Contribuição número 783 do Departamento de Zoologia, Universidade Federal do Paraná.

2) Departamento de Zoologia, Universidade Federal do Paraná, Caixa Postal 19020, 81531-970 Curitiba, Paraná, Brasil. 

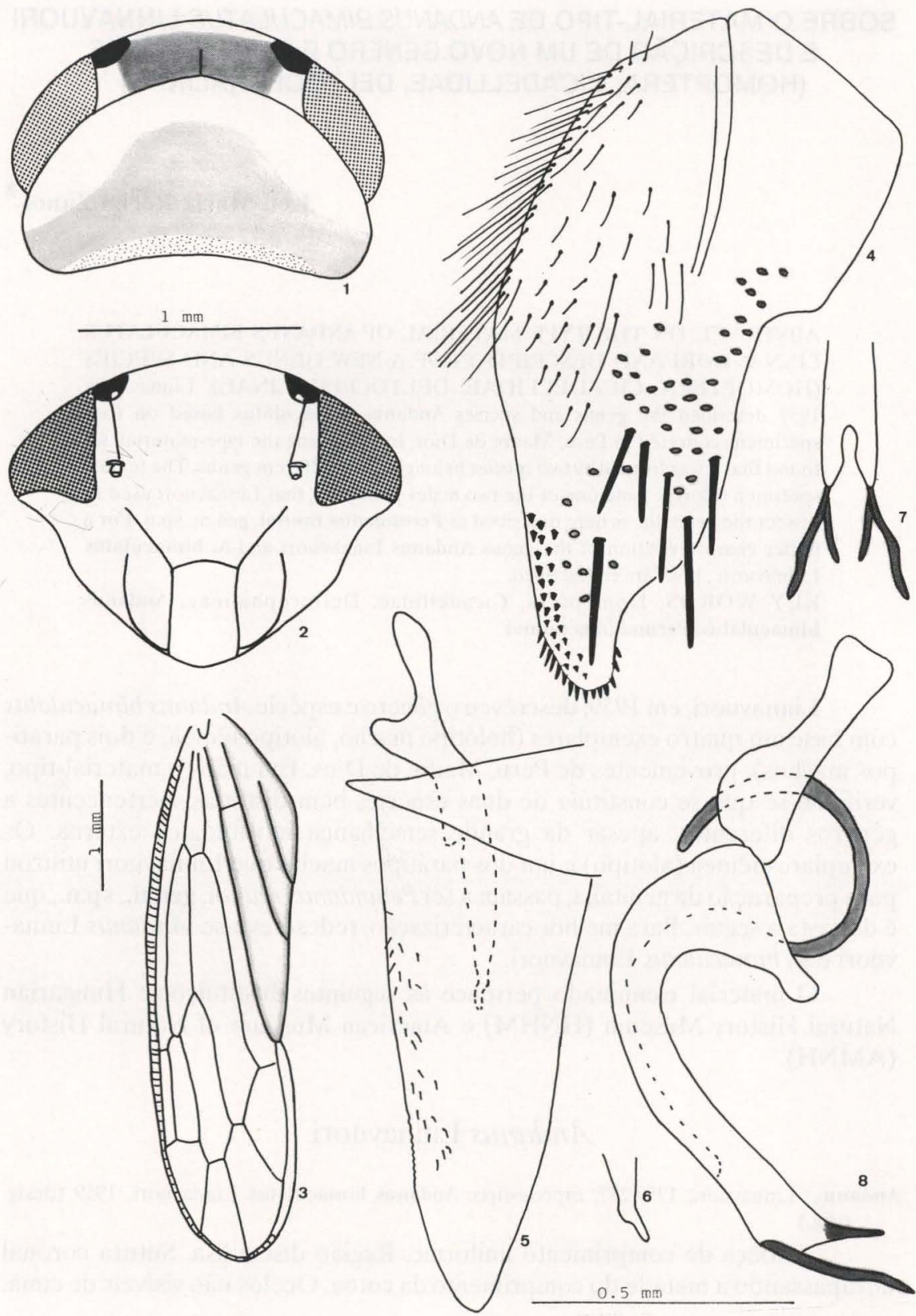

Figs 1-8. Andanus bimaculatus Linnavuori, holótipo. (1) Cabeça e pronoto, dorsal; (2) face; (3) tégmina. (4-8) Genitália. (4) pigóforo, lateral; (5) valva, placa subgenital e estilo; (6) ápice estilo; (7) ápice do edeago, dorsal; (8) edeago, lateral. 
Distância ocelo-ocular igual ao diâmetro dos ocelos. Olhos, em vista ventral, sem emarginação omatidial. Sutura transclipeal arqueada. Genas sinuosas. Anteclípeo tão longo quanto as genas; mais largo no ápice; plano.

Pronoto mais estreito que a cabeça; superfície lisa; margens laterais lisas, curtas. Tégminas sem falsas veias; com duas células anteapicais, a externa retangular. Margem costal sem veias extranumerárias. Clavo com veia extranumerária entre $1 \mathrm{~A}$ e a sutura. Primeira célula discal longa, alcançando a célula anteapical externa. Transversa s-m após a bifurcação da $\mathbf{S}$; a s presente. Apêndice curto, não alcançando $\mathbf{M}_{3}+4$. Espinulação das tíbias anteriores $1+4$ e dos fêmures posteriores $2+2+1$.

Genitália. Macho: valva genital semicircular. Placa subgenital triangular; ápice arredondado; sem macrocerdas. Pigóforo com macrocerdas; sem apêndices. Tubo anal sem apêndices. Estilos curtos. Pseudóstilos ausentes. Edeago simétrico, com apêndices apicais, base projetada em apódema; gonoduto esclerotinizado antes da base do edeago.

Comentário. Próximo a Neocrassana Linnavuori no aspecto geral e pelo gonoduto esclerotinizado antes da base do edeago; difere na posição dos ocelos, comprimento da sutura coronal, pela ausência de macrocerdas nas placas subgenitais, ausência de apêndices no pigóforo e pela presença de apêndices no edeago.

\section{Andanus bimaculatus Linnavuori}

Figs 1-8

\section{Andanus bimaculatus Linnavuori, 1959: 238}

Macho. Coloração: coroa amarelada; margem anterior com duas manchas arredondadas pretas, junto aos olhos; região discal com uma mancha transversa alaranjada, entre as manchas pretas e a margem posterior da cabeça. Face amarela. Pronoto amarelado, com uma mancha mais ou menos trapezoidal amarelo-ouro, com nuanças alaranjadas; margem posterior com uma estreita faixa transversa marrom. Escutelo laranja-claro, com uma faixa transversa marrom na margem anterior. Tégminas transparentes; contorno do clavo e veias anais amarelos; demais veias concolores.

Genitália. Placas subgenitais com superfície interna lisa. Pigóforo com inúmeras setas apicais e longos pêlos na metade basal. Estilos com apófise longa; ápice mais estreito e levemente falciforme. Edeago curvo para cima, com dois pares de apêndices apicais, voltados para cima: o par maior sinuoso, divergente e o outro, mais ventral, convergente. Gonoduto em forma de um semicírculo, passando por um orifício no conetivo.

Tamanho: $6,00 \mathrm{~mm}$

Fêmea. Desconhecida.

Holótipo macho de "Peru, Madre de Dios, Andanus bimaculatus gen.n. et sp., det. Linnavuori. Typus (HNHM)". Parátipo macho da mesma localidade (Coll.Mus.Nat.Hung.) (AMNH). 


\section{Perundanus, gen.n.}

Andanus Linnavuori, 1959: 237 (Partim)

Espécie-tipo: Perundanus raunoi, sp.n.

Cabeça de comprimento uniforme. Região discal microesculturada. Sutura coronal ultrapassando a metade do comprimento da coroa. Ocelos não visíveis de cima. Distância ocelo-ocular igual ao diâmetro dos ocelos. Olhos, em vista ventral, sem emarginação omatidial. Sutura transclipeal arqueada. Genas sinuosas. Anteclípeo levemente mais longo que as genas, mais largo no ápice, plano.

Pronoto mais estreito que a cabeça; superfície dorsal lisa; margens laterais lisas, curtas. Tégminas sem falsas veias; com 2 células anteapicais; a externa retangular. Margem costal sem veias extranumerárias. Clavo com veia extranumerária entre $1 \mathrm{~A}$ e a sutura claval. Primeira célula discal longa, alcançando a célula anteapical externa. Transversa s-m após a bifurcação da $\mathbf{S}$ (muito curta); a s presente. Apêndice curto, não alcançando M3 + 4. Espinulação das tíbias anteriores $1+4$ e dos fêmures posteriores $2+2+1$.

Genitália. Fêmea: placa subgenital inteira. Macho: valva genital triangular com os ângulos arredondados. Placa subgenital triangular; macrocerdas unisseriadas. Pigóforo com macrocerdas; sem apêndices. Tubo anal sem apêndices. Estilos longos. Pseudóstilos ausentes. Edeago simétrico; com apêndices subapicais. Gonoduto não esclerotinizado antes da base do edeago.

Comentário. Este gênero difere de Andanus Linnavuori no padrão de coloração, pela valva genital triangular, espinulação do pigóforo, presença de macrocerdas nas placas subgenitais, gonoduto não esclerotinizado antes da base do edeago; estilos longos e pelo formato dos apêndices do edeago.

O nome genérico provém do local onde foram os espécimens coletados associado ao antigo gênero ao qual a espécie havia sido incluída: Peru + Andanus.

\section{Perundanus raunoi, sp.n.}

Figs 9-15

Andanus bimaculatus Linnavuori, 1959 (partim).

Coloração. Coroa amarela; margem anterior com duas manchas arredondadas, pretas, junto aos olhos. Face amarela; anteclípeo marrom-escuro, em quase toda sua extensão; lora marrons; genas com uma faixa marrom-escura, ao longo da sutura frontoclipeal desde as lora até os alvéolos antenais.Pronoto amarelo com uma faixa transversa, sobre o disco, marrom. Tégminas marrons, semitransparentes; contorno do clavo e veias anais amarelas; demais veias concolores; margem costal marrom.

Genitália. Fêmea: placa subgenital inteira com uma grande elevação ovalada no meio. Macho: valva triangular com os ângulos arredondados. Placa subgenital triangular; ápice afilado; superfície interna com dobra. Ápice dos estilos alargado. Pígoforo com pequenas setas apicais; as poucas macrocerdas 

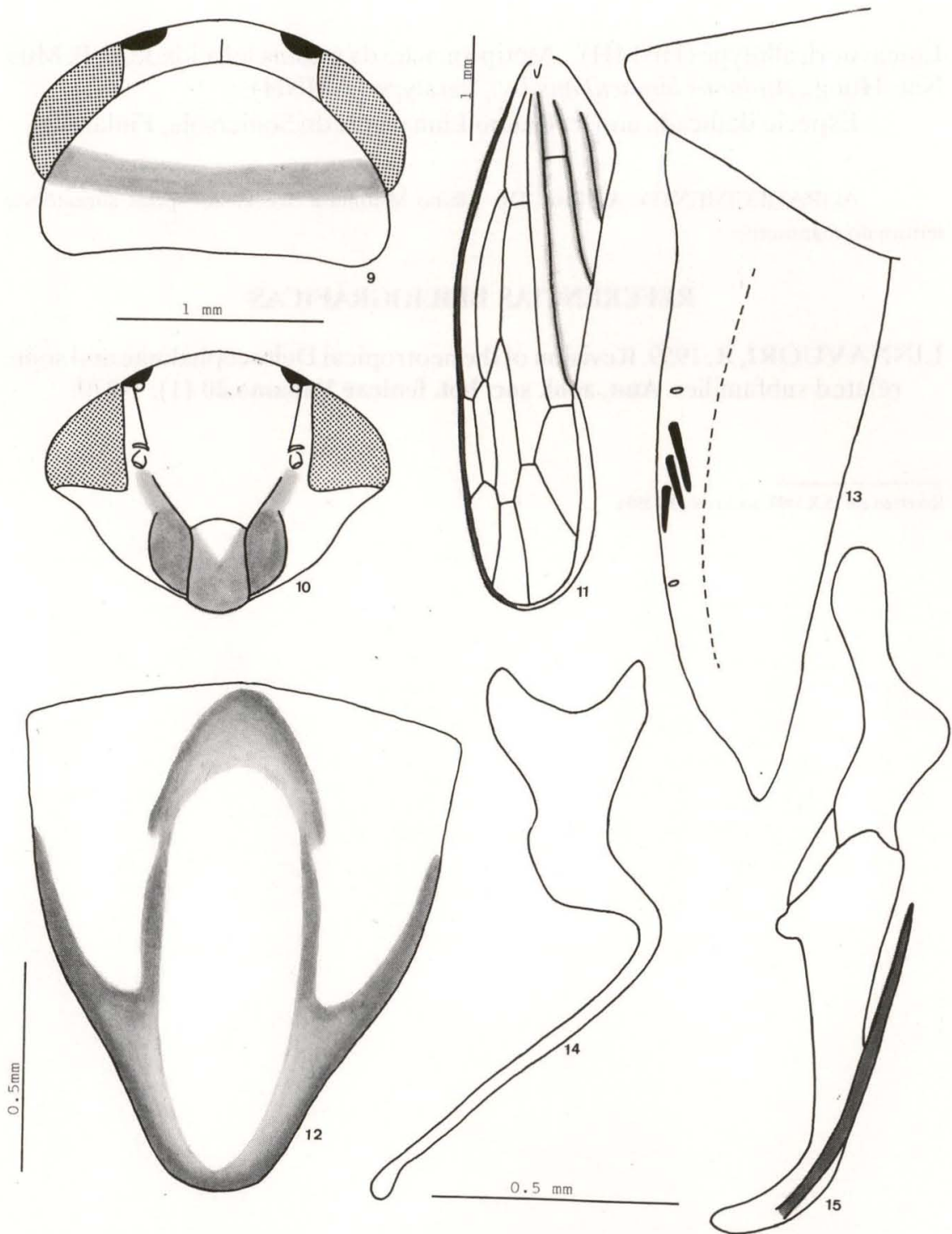

Figs 9-15. Perundanus raunoi, sp.n., holótipo. (9) Cabeça e pronoto, dorsal; (10) face; (11) tégmina; (12) placa subgenital. (13-15) Genitália macho, parátipo. (13) Valva e placa subgenital; (14) estilo, lateral; (15) edeago, lateral.

próximas ao tubo anal. Edeago com o terço apical curvo para cima; um par de apêndices subapicais, voltados para trás, convergentes, quase tão longos quanto o próprio edeago.

Tamanho. Macho: 6,00mm; fêmea: $6,60 \mathrm{~mm}$.

Holótipo fêmea de "Peru, Madre de Diós. Andanus bimaculatus, det 
Linnavuori, allotype (HNMH)". Alótipo macho da mesma localidade, coll. Mus. Nat. Hung., Andanus bimaculatus Lv., Paratype (AMNH).

Espécie dedicada ao Dr. Rauno Linnavuori do Somersoja, Finlândia.

AGRADECIMENTO. Ao Prof. Dr. Albino Morimasa Sakakibara, pelas sugestões e leitura do manuscrito.

\section{REFERÊNCIAS BIBLIOGRÁFICAS}

LINNAVUORI, R. 1959. Revision of the neotropical Deltocephalinae and some related subfamilies. Ann. zool. soc. bot. fenicae Vanamo 20 (1): 1-370.

Recebido em 15.X.1993; aceito em 22.II.1994. 